\title{
Terapia fotodinâmica em dermatologia: princípios básicos e aplicações
}

\author{
Photodynamic therapy in dermatology: basic principles and clinical use
}

Luís Torezan $^{1}$

Ane Beatriz Mautari Niwa ${ }^{2}$

Cyro Festa Neto ${ }^{3}$

Resumo: A terapia fotodinâmica envolve a administração de uma droga fotossensibilizante e sua ativação subsequente pela luz de comprimento de onda correspondente ao espectro de absorção do fotossensibilizador. Atualmente, a terapia fotodinâmica tópica é aprovada para o tratamento de condições oncológicas cutâneas como queratoses actínicas, doença de Bowen e carcinoma basocelular superficial em diversos países do mundo. Estudos multicêntricos controlados e randomizados demonstram a alta eficácia e resultado cosmético final superior dessa modalidade terapêutica em relação aos tratamentos convencionais. Para condições cutâneas não oncológicas, como acne vulgar, verrugas virais e esclerodermia localizada, há também relatos e série de casos confirmando o potencial terapêutico da terapia fotodinâmica. O desenvolvimento de fotossensibilizantes tópicos, ácido 5-aminolevulínico (ALA) ou seu metiléster (MAL), frente aos derivados da hematoporfirina de aplicação sistêmica, permitiu um grande avanço na popularidade da TFD na dermatologia, uma vez que tanto ALA quanto MAL tópicos não induzem mais fotossensibilidade generalizada prolongada. A produção de intermediários reativos de oxigênio, como oxigênio singlet, depende da concentração, da localização do fotossensibilizante no tecido alvo, assim como da dose de luz utilizada. Tanto as lâmpadas de amplo espectro quanto os LEDs (do inglês light emitting diodes) constituem fontes de luz adequadas para que os efeitos citotóxicos da terapia fotodinâmica resultem na destruição do tumor ou seus efeitos imunomodulatórios atuem melhorando as condições inflamatórias cutâneas.

Palavras-chave: Carcinoma basocelular; Carcinoma in situ; Fotoquimioterapia

\begin{abstract}
Photodynamic therapy involves the administration of a photosensitizing drug and its subsequent activation by light at wavelengths matching the absorption spectrum of the photosensitizer. Currently, topical photodynamic therapy has received approval for the treatment of cutaneous oncologic conditions such as actinic keratoses, Bowen's disease and superficial basal cell carcinoma in many countries in the world. Multicenter randomized controlled studies have demonstrated high efficacy and superior cosmetic outcome over standard therapies. For many non-oncologic dermatological diseases such as acne vulgaris, viral warts and localized scleroderma, case reports and small series have confirmed the potential of photodynamic therapy. After the development of topical photosensitizers 5aminolevulinic acid (ALA) or its methyl ester (MAL), photodynamic therapy has gained worldwide popularity in dermatology, as these drugs do not induce prolonged phototoxicity as the systemic photosensitizing hematoporphyrin derivatives do. The production of reactive oxygen intermediates such as singlet oxygen depends on the concentration and localization of the photosensitizer in the diseased tissue as well as the applied light dose. Either incoherent lamps or LED arrays are suitable for the cytotoxic effects resulting in tumor destruction or immunomodulatory effects improving inflammatory condition. Keywords: Carcinoma, basal cell; Carcinoma in situ; Photochemotherapy
\end{abstract}

Aprovado pelo Conselho Editorial e aceito para publicação em 16.06.2009.

* Trabalho realizado no ambulatório de terapia fotodinâmica do Departamento de Dermatologia do Hospital das Clínicas da Universidade de São Paulo - São Paulo (SP), Brasil.

Conflito de interesse: Nenhum / Conflict of interest: None

Suporte financeiro: Nenhum / Financial funding: None

Mestre em dermatologia pela Faculdade de Medicina da Universidade de São Paulo (FMUSP), doutorando pelo Departamento de Dermatologia da Faculdade de Medicina da Universidade de São Paulo (FMUSP) - São Paulo (SP), Brasil.

Médica dermatologista, pós-graduanda pelo Departamento de Dermatologia da Faculdade de Medicina da Universidade de São Paulo (FMUSP) - São Paulo (SP), Brasil.

Professor doutor pela Faculdade de Medicina da Universidade de São Paulo (FMUSP) e livre docente pela Faculdade de Medicina da Universidade de São Paulo (FMUSP) - São Paulo (SP), Brasil.

(C)2009 by Anais Brasileiros de Dermatologia

An Bras Dermatol. 2009;84(5):445-59 


\section{INTRODUÇÃO}

A terapia fotodinâmica (TFD) é uma modalidade terapêutica que tem sido usada no tratamento de vários tumores malignos em diversas áreas da medicina.

Na dermatologia, a TFD é empregada no tratamento do câncer de pele não-melanocítico (CPNM) e outras doenças inflamatórias e proliferativas não neoplásicas como psoríase, doença de Darier, sarcoidose e necrobiose lipoídica. Nas últimas décadas, a TFD progrediu de um recurso terapêutico experimental para primeira opção no tratamento de lesões como queratoses actínicas (QA) e outras lesões superficiais extensas como carcinoma basocelular superficial (CBC) e doença de Bowen (DB).1.3

Hoje em dia, vemos um crescimento enorme da TFD e suas aplicações. Por um lado parece fascinante, por outro, até meio controverso através da combinação de várias drogas, protocolos, fontes de luz, novas indicações, que podem desorientar o profissional médico que esteja iniciando sua experiência com TFD. Neste sentido, a compreensão dos princípios básicos assim como o conhecimento dos agentes, fontes de luz e mecanismo de ação tornam-se imperativos para a boa realização da técnica e obtenção dos melhores resultados.

\section{HISTÓRICO}

A TFD tem sua origem no início do século XX, em Munique, quando Oscar Raab, um estudante de medicina orientado pelo Professor Herman Von Tappeiner, observou os efeitos decorrentes da fotossensibilização em paramécio. ${ }^{4} \mathrm{O}$ interesse do estudo era identificar o processo onde a droga quinina era eficaz contra a malária, enquanto outros agentes como a acridina (derivado do coaltar) eram tóxicos contra protozoários in vitro, porém não, in vivo. Raab observou que o paramécio morria entre 60 e 100 minutos após acridina, na concentração de 1:20.000, ter sido adicionada ao meio. Em outro experimento, o paramécio sobrevivia por 800 a 1000 minutos com a mesma concentração de acridina. A única diferença foi a ocorrência de uma grande tempestade, acarretando condições adversas de luminosidade ambiente e, assim, os pesquisadores passaram a indagar se a luz tinha influência nos resultados. A continuação dos estudos confirmou que a acridina e a luz aumentavam a toxicidade ao paramécio, enquanto acridina isolada,

luz isolada ou acridina exposta à luz e, posteriormente adicionada ao meio, eram atóxicas. ${ }^{4-8}$

Em 1960, foi sintetizado um composto purificado da hematoporfirina chamado HpD. Nas décadas de 1970 e 80, estudos foram realizados com a utilização de um derivado purificado do $\mathrm{HpD}$ conhecido com Porfimer sódico, para tratamento de tumores de bexiga, pulmão, esôfago, estômago, pele e aparelho gine- cológico.9-12 No início da década de 1990, no Canadá, o Porfimer sódico foi a primeira droga aprovada para uso terapêutico. 9

A fotossensibilidade prolongada com o uso de drogas sistêmicas, os altos índices de cura obtidos com outros métodos mais práticos diminuíram o interesse deste método na dermatologia. Neste sentido, novas drogas, chamadas de segunda geração, foram desenvolvidas e contribuíram para os recentes avanços da TFD na dermatologia.

Em 1990, Kennedy e cols revolucionaram a TFD através do uso de uma substância tópica: o ácido 5delta aminolevulínico (5-ALA). Trata-se de um precursor porfirínico (protoporfirina IX ou PpIX) que é sintetizada no interior das células através da biossíntese do grupo Heme. ${ }^{13}$ A PpIX é considerada potente agente fotossensibilizante e facilmente fotoinativado. ${ }^{13,14}$ No fim da década de 1990, uma nova droga derivada do 5-ALA foi sintetizada-o metilaminolevulinato. Tratase de um composto esterificado do 5-ALA, que por ter propriedade lipofílica, apresenta a vantagem de maior penetração e especificidade no tecido tumoral. $\mathrm{O}$ mecanismo de ação parece ser o mesmo para ambas as drogas.

Assim a TFD com droga tópica é capaz de induzir fotossensibilidade localizada e seletiva na área cutânea a ser tratada como em CBC superficiais, CEC superficiais (in situ) e QAs. 1,13,14

\section{Agentes Fotossensibilizantes Agentes tópicos}

5- ALA e MAI

ALA é um agente hidrofílico sendo captado pelas células, principalmente, através de transporte ativo, como $\mathrm{Na}+/ \mathrm{Cl}$ - dependente de beta aminoácidos como glicina e ácido gama aminobutírico (GABA) carregadores. ${ }^{15}$ Esses sistemas requerem energia, dependem de $\mathrm{pH}$ e temperatura, são lentos e saturáveis e estão um pouco mais acelerados em células tumorais. ${ }^{15}$ MAL é uma molécula lipofílica sendo captada por mecanismos de transporte ativos principalmente dependentes de aminoácidos não-polares como alanina, metionina, triptofano e glicina. Porém, o MAL também é captado por mecanismos passivos de difusão transmembrana.15,16 Esse mecanismo não requer energia e não é saturável, sendo eficaz em células normais, porém, mais ainda em células neoplásicas. Essa pluralidade de fatores talvez explique a maior penetração do MAL em relação ao ALA, sobretudo em células malignas.

O ALA é o primeiro intermediário na via de biossíntese do grupo Heme, sendo sintetizado a partir da glicina e succinil - Coa, no interior da mitocôndria (Figura 1). ${ }^{17}$ Essa reação é catalisada pela enzima ALAsintetase. Já no citoplasma da célula, 2 moléculas de 


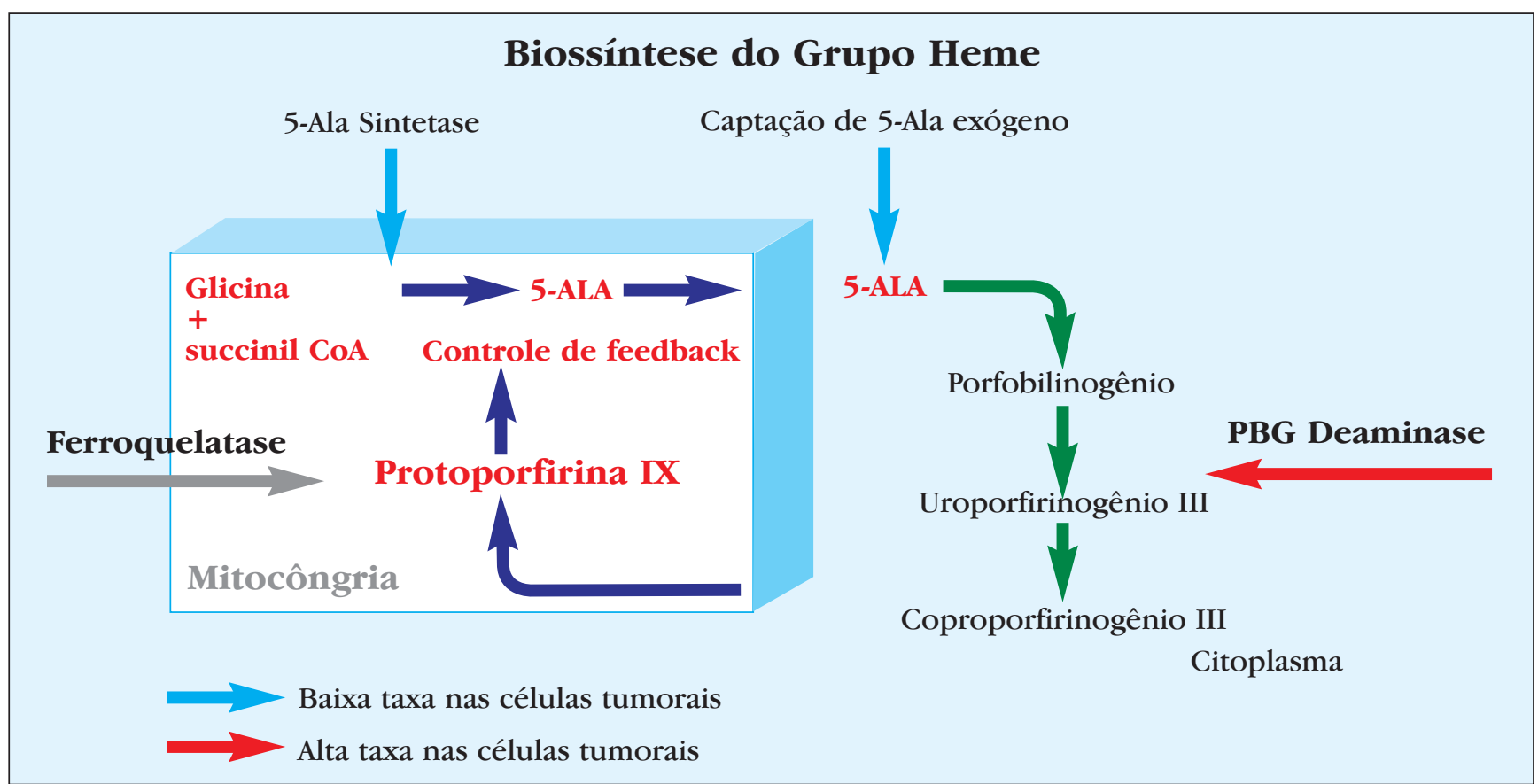

Figura 1: Captação do ALA exógeno e biossíntese do Heme

ALA formam o porfobilinogênio (PBG) e 4 moléculas de PBG formam o uroporfirinogênio III. Este último é convertido em coproporfirinogênio III e, novamente no interior da mitocôndria, em protoporfirinogênio IX, que é convertido em PpIX, pela ação da protoporfirinogênio oxidase. $16,18,19$

A PpIX é o intermediário porfirínico com atividade fotodinâmica e, quando ativado por luz azul, emite fluorescência vermelha intensa.

A síntese normal de ALA, no interior da célula, é controlada pela enzima ALA sintetase que, por sua vez, é inibida pelo acúmulo de Heme (feedback negativo). Se um excesso de ALA exógeno for aplicado topicamente, ocorrerá rápida passagem através da epiderme anormal e posterior conversão à PpIX no interior da mitocôndria. Uma vez que a conversão da PpIX para Heme é uma reação lenta, as células tendem a acumular grande concentração de PpIX. $\mathrm{O}$ acúmulo excessivo de PpIX no interior da mitocôndria induz à sua difusão para o reticulo endoplasmático e membrana celular, ambos alvos finais do dano celular induzido pela TFD.

Quando MAL é aplicado topicamente, a molécula é rapidamente demetilada a ALA e sofre o mesmo processo de metabolização, conforme exposto acima. ${ }^{15}$

A PpIX possui vários picos de absorção da luz. O principal é na banda de Soret em 405 nm, correspondente à luz azul. Outros picos menores também têm importância e são chamados de " $Q$ bands" ou bandas Q. São picos que ocorrem em 510, 545, 580, 630, 670 e $700 \mathrm{~nm}$ (Gráfico 1). ${ }^{17}$ Embora os picos das bandas Q sejam 10 a $40 \times$ menores que o pico em 405 $\mathrm{nm}$, muitos estudos em TFD são conduzidos usando fonte de luz no espectro da luz vermelha entre $620 \mathrm{e}$ $635 \mathrm{~nm}$, que proporciona maior penetração no tecido, otimizando a TFD para lesões mais profundas. Porém, fontes de luz azul e verde também são empregadas em TFD para lesões mais superficiais e com resultados semelhantes. 15,16,18-22

Alguns fatores interferem com a penetração do ALA na pele: concentração, tipo de veículo utilizado na sua preparação, tempo de aplicação e uso de agentes coadjuvantes que favorecem o acúmulo de PpIX nas células tumorais. Nos estudos clínicos, as concentrações de ALA variam de 5 a 20\%.15,16,21,23 Os melhores resultados terapêuticos foram obtidos com concentrações entre 10 e 20\%.15,16,18-24 Hoje, utilizam-se ALA 20\% em emulsão água/óleo e solução hidroalcóolica (disponível comercialmente em forma de bastão, sendo o pó do ALA separado da solução, para uso tópico). ${ }^{22}$ Já o MAL somente está disponível em forma de creme contendo óleo de archis, glicerila e água na concentração de $16 \%$ disponível comercialmente em forma de tubo contendo $2 \mathrm{~g}$, pronto para uso tópico. ${ }^{25-28}$

Quanto ao fator tempo de aplicação sobre a lesão, também existe grande variação de 3 a 20 horas. 13,14,20, 29-31 Alguns trabalhos recentes utilizam ALA sem oclusão com tempo de aplicação de 15 a 60 minutos para fotorejuvenescimento e acne. ${ }^{22}$ Hoje, os protocolos aprovados para o uso de ALA tópico no tratamento de QAs são de aplicação prolongada entre 14 e 18 horas.22,28 No caso do MAL, o tempo de aplicação é de 3 horas sob oclusão. ${ }^{28}$ 


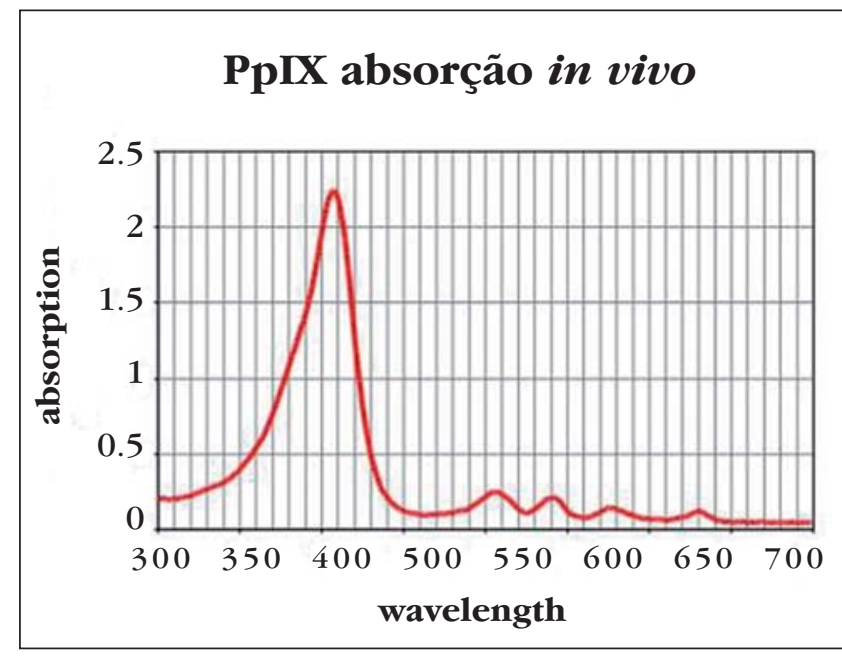

GráfICO: Espectro de absorção da PpIX

Fonte: Torezan $L^{17}$

O uso de agentes coadjuvantes em formulações com ALA pode aumentar, direta ou indiretamente, a formação de PpIX na célula tumoral. A adição de agentes que inibam a ação da enzima ferroquelatase ou aumentem a penetração do ALA no tecido, como ocorre com a desferroxamina, o ácido dietilaminotetracético (EDTA) e dimetilssulfóxido (DMSO) constituem exemplos de aditivos que potencializam a TFD. ${ }^{21}$ Outras técnicas também podem aumentar a concentração de PpIX por aumentar a absorção de ALA, como é o caso da iontoforese. 32

\section{MECANISMO DE AÇÃO}

O conceito da TFD é a indução da citotoxicidade das células proliferativas por meio de uma fonte de luz. Para que isso ocorra, são necessários 3 componentes: agente fotossensibilizante, luz e oxigênio.9,10

A técnica, em geral, consiste de duas etapas. $\mathrm{Na}$ primeira, o agente fotossensibilizante acumula-se nas células tumorais após a administração tópica ou sistêmica. Na segunda, o tumor fotossensibilizado é exposto à luz de comprimento de onda que coincida com o espectro de absorção do agente fotossensibilizante. 9,10,15,16,22,31

Durante a TFD, o agente fotossensibilizante ligado ao tumor é ativado na presença de luz. Essa ativação leva-o do estado de repouso ao estado de ativação chamado singlet, de meia vida curta. Nessa etapa, as moléculas podem retornar ao estado de repouso, emitindo energia em forma de fluorescência por meio da liberação de fótons ou progredir na cadeia de reações químicas, até atingir o estado triplet de meia vida mais longa. As moléculas no estado triplet transferem sua energia diretamente ao oxigênio intracelular, formando o oxigênio singlet $\left({ }^{1} \mathrm{O}_{2}\right)$, altamente reativo, de meia vida curta e responsável pela morte celular.9,10

Em conseqüência da ação do ${ }^{1} \mathrm{O}_{2}$, a célula tumoral passa a apresentar falhas na integridade da membrana, o que acarreta alterações na permeabilidade e função de transporte entre os meios intra e extracelulares. Alterações nas membranas do núcleo, mitocôndria, lisossomos e retículo endoplasmático também ocorrem.15,16,33 Estudos utilizando microscopia de fluorescência sugerem que a fototoxicidade mitocondrial é a principal causa da morte celular induzida pela TFD. ${ }^{15,33}$ A despeito da exata localização do efeito citotóxico, a conseqüência é a perda da integridade celular, havendo a liberação de fatores inflamatórios e ativação da cascata do complemento. ${ }^{16}$

Durante a TFD, a seletividade do tratamento depende da área exposta à luz e do acúmulo preferencial do agente fotossensibilizante nas células tumorais em relação ao tecido normal. Embora esse acúmulo preferencial seja pouco compreendido, alguns fatores são apontados como responsáveis. ${ }^{9,16,28}$ A permeabilidade da membrana das células tumorais está alterada. Esse fato pode ser comprovado pela rápida passagem de corantes, como azul de Evans e vermelho do Congo, do interior dos capilares para o estroma do tumor. ${ }^{9,10}$ As fibras colágenas que integram o tumor são imaturas e semelhantes às observadas em tecido embrionário e processo de cicatrização recente. Essas fibras imaturas apresentam grande capacidade de ligação às porfirinas, constituindo um local para retenção e acúmulo do agente fotossensibilizante. ${ }^{9}$ Outros fatores também colaboram: rede linfática pouco desenvolvida, ligação das porfirinas a receptores de superfície de lipoproteínas de baixa de densidade das células tumorais, presença de macrófagos e menor $\mathrm{pH}$ intracelular. 9,10

\section{Fontes de Luz}

Três diferentes grupos de fontes de luz podem ser caracterizados para a TFD: lâmpadas de amplo espectro, lâmpadas de diodo e lasers. A ação destes aparelhos depende fundamentalmente do espectro de emissão, da irradiância, da distribuição espacial da luz e da potência do aparelho. 9,10,15,16

A emissão das lâmpadas de amplo espectro de alta pressão ou fluorescentes abrangem quase toda a luz visível e início do infravermelho, poupando, quase totalmente, a radiação U-V. Lâmpadas halógenas metálicas são amplamente usadas, pois são mais baratas e têm alta irradiância, que mantêm a exposição da luz constante e promove uma TFD não muito longa. Podem ser usadas como fonte de projetores de slides (luz branca) ou equipadas com filtros ópticos que promovem a seleção da banda de luz que se deseja. A lâmpada fluorescente mais usada opera na faixa da luz azul em $407 \mathrm{~nm}$ (banda de Soret), sendo suficiente para promover ativação fotodinâmica do 5 - ALA (Blu$\mathrm{U}^{\circledR}$, Dusa Phramaceuticals, USA). $34-36$ 
Os LEDs (do inglês, "light emitting diodes") são aparelhos compostos por semi-condutores sólidos ligados entre si e que geram luz. Fornecem uma fonte de luz confiável e de alta potência em faixas estreitas de bandas de luz (entre $20-50 \mathrm{~nm}$ ) e podem ser distribuídas em painéis para promover a iluminação de uma superfície ampla e homogênea. Este último item é muito importante, pois uma distribuição irregular da luz pode deixar de tratar partes de um tumor superficial mais extenso. São de fácil uso e de meia vida longa. ${ }^{15}$

A irradiância e a uniformidade da irradiação devem ser constantemente checadas durante a TFD. As irradiâncias usadas em TFD variam de 50 a 150 $\mathrm{mW} / \mathrm{cm}^{2}$. Em irradiâncias muito baixas o tempo de exposição à fonte de luz pode ser muito longo, enquanto que, em irradiâncias muito altas, pode ocorrer efeito térmico aditivo na TFD. Durante a irradiação do tumor ocorre um processo conhecido como fotoinativação da droga fotossensibilizante (do inglês, "photobleaching"), ou seja, à medida que o tumor é destruído pela ativação fotodinâmica ocorre, paralelamente, inativação do agente pela absorção da luz. 9,10

Ao contrário das lâmpadas, os lasers fornecem luz em comprimento de onda específico que pode ser compatível com o principal espectro de absorção do agente fotossensibilizante, além de um feixe de luz bastante homogêneo. Muitos lasers já foram usados em TFD como "argon dye laser", Nd: YAG, "copper vapour dye", "gold vapour" e "diode laser". ${ }^{15,16} \mathrm{O}$ seu uso permite a realização da TFD mais rápida, pois emitem alta fluência de luz monocromática que corresponde ao pico de absorção do agente. Porém, são aparelhos caros, não são portáteis, demandam mais assistência técnica e iluminam apenas pequenas áreas da pele.

Quando se avaliam as diversas publicações de TFD com lasers ou fontes de luz não-coerentes (LEDs e lâmpadas halógenas), é importante ressaltar que as fluências só podem ser comparadas quando consideradas as respectivas irradiâncias dos aparelhos. Por exemplo, lâmpadas halógenas de amplo espectro emitem fótons em comprimentos de onda muito curtos ou muito longos que não são necessários para a ativação do agente fotossensibilizante, resultando fótons desprezados e acarretando superestimação da fluência efetiva quando comparados aos lasers. 9,10,16

\section{APLICAÇÕES CLÍNICAS ONCOLÓGICAS EM DERMATOLOGIA:}

5-ALA e MAL

Metilaminolevulinato (Metvix ${ }^{\star}$ Galderma, France) é aprovado nos países da Comunidade Européia, América Latina, Austrália, Nova Zelândia, e nos Estados Unidos e 5- ALA (Levulan Kerastisck ${ }^{\circledR}$, Dusa Pharmaceuticals, USA) nos Estados Unidos e
Canadá como precursores fotossensibilizantes tópicos para TFD. A escolha correta da fonte de luz é de extrema importância. Embora a luz azul possibilite ativação fotodinâmica e penetração suficiente para o tratamento das QAs superficiais, a luz vermelha oferece maior penetração no tecido, sendo mais efetiva nas lesões mais espessas como os CBCs. O protocolo de tratamento com 5-ALA é feito com fonte de luz azul fluorescente de $417 \mathrm{~nm}$ na dose total de $10 \mathrm{~J} / \mathrm{cm}^{2}$ (Blu-U, Dusa Pharmaceuticals, USA) enquanto que, com MAL, a fonte de luz é um LED de $635 \mathrm{~nm}$ na dose total de $37 \mathrm{~J} / \mathrm{cm}^{2}$.

Os estudos publicados de TFD para tratamento das QAs envolvem ALA e MAL. Todas as evidências mostram que a TFD é altamente eficaz. A resposta completa das lesões com MAL, após 3 meses de seguimento, mostram $90 \%$ de cura e cerca de 89\%a 91\% para ALA, no mesmo período de seguimento. $25,26,34,35,37,38$ Em recente publicação, Tarstedt e cols, observaram que apenas uma sessão de MAL-TFD, repetida 3 meses após se necessário, era igualmente eficaz e com índice de cura de $92 \%$, semelhante ao protocolo inicial. ${ }^{38}$ Assim, para o tratamento das QAs com MAL, preconiza-se apenas uma sessão e, se necessário, nova sessão após 3 meses, nos casos de resposta parcial. Cabe ressaltar que sempre se faz o preparo das lesões antes da aplicação do MAL, ou seja, uma leve curetagem das lesões com o intuito de remover as camadas mais superficiais de queratina.

Os estudos que comparam TFD com criocirurgia e 5-fluoracil mostram eficácia no mínimo igual ou superior com a TFD. Porém, o resultado cosmético final obtido com a TFD sempre foi superior em todas as publicações. Os estudos mostram excelente resultados cosméticos entre $91 \%$ e $98 \%$ dos pacientes tratados. $22,28,39,40$

Em relação à doença de Bowen (DB), os estudos conduzidos com ALA (em geral ALA 20\% em formulação com creme e com fontes de luz variáveis) mostram índices de cura de $88 \%$ a $100 \% .28,39-41$ No maior estudo multicêntrico conduzido por Morton e cols, o índice de cura inicial foi de 93\%. Após 24 meses, a recorrência foi de $18 \%$. Nesse mesmo estudo, que foi comparativo com criocirurgia e 5- fluoracil, a recorrência com esses últimos foi de $23 \%$ e $21 \%$ respectivamente. ${ }^{41}$ Porém, o efeito cosmético final, assim como a preferência pelo método, foi bem superior na TFD quando comparada aos demais (Figuras 2 e 3 ). 42

A TFD também é considerada uma modalidade não invasiva para os $\mathrm{CBCs}$ superficiais, com vários estudos que suportam o seu uso.28,43-45 Em recente estudo multicêntrico conduzido por Basset-Seguin e cols, o índice de cura foi de $97 \%$ após 3 meses de seguimento. Em seguimento maior de 5 anos, a taxa de recorrência observada foi de $22 \%$. O estudo foi 

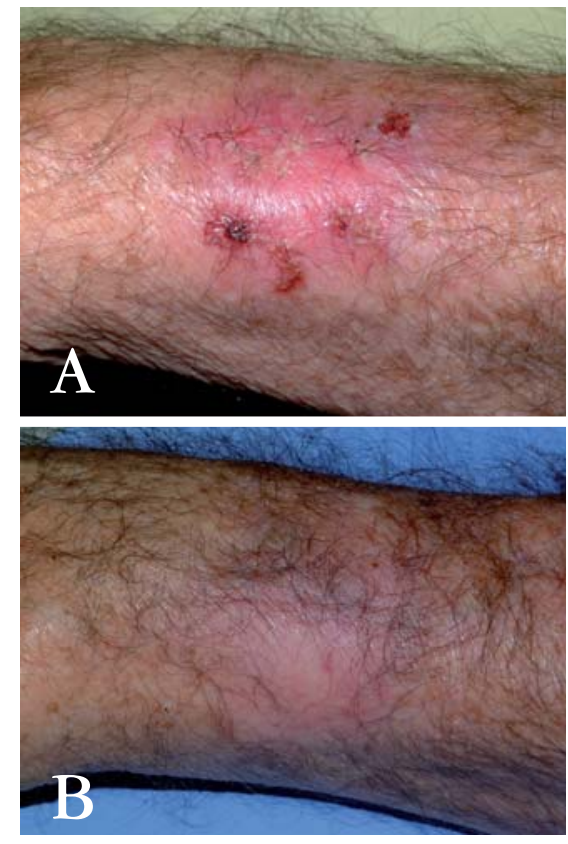

Figura 2: A. Doença de Bowen no antebraço esquerdo pré; B. Tratamento após seis meses de MAL-PDT comparado com a criocirurgia que mostrou índice de cura inicial de $95 \%$ e recorrência de $20 \%$ após 5 anos, sem diferença estatisticamente significante entre os métodos. Fato de relevância foi o aspecto cosmético final, com ampla vantagem para TFD frente ao incômodo pós-operatório e distúrbios de cicatrização mais freqüentes com a criocirurgia. ${ }^{44}$ Nos pacientes portadores de CBC superficial e/ou nodular de "difícil tratamento" (lesões extensas, recorrentes, locais de ruim cicatrização ou pacientes portadores de doenças sistêmicas que dificultem a cicatrização), índices de recorrência de 15\% a 31\% foram observados, após 36 meses de seguimento. ${ }^{46,47}$ Para o tratamento dos CBCs com MAL, preconizam-se 2 sessões $\mathrm{cm}$ intervalo de 7 dias.

Embora as taxas de recorrência sejam maiores, a PDT deve ser considerada uma boa opção frente a situações onde a cirurgia possa ser impeditiva. ${ }^{27}$ Estudos menores com ALA e TFD foram feitos para CBC superficiais, mostrando eficácia de $90 \%$ a $100 \%$ (ALA 20\% e lâmpadas halógenas). 20,21,23,24,29,30,43,48,49 (Figura 4)

O uso de drogas tópicas na TFD para CBC nodular é crítico, pois tanto a luz quanto a penetração da droga no tecido acabam limitando os resultados. MAL apresenta melhor penetração nos CBCs nodulares do que ALA, pela maior lipofilicidade e menor carga polar. No protocolo de MAL para CBCs nodulares, preconizase a curetagem da parte superior do tumor, mesmo que haja sangramento, imediatamente antes da aplicação do produto. ${ }^{28} \mathrm{Na}$ maioria das vezes, pode-se conter o sangramento apenas comprimindo o local.

Muitos estudos com TFD apresentam índices de cura de $50 \%$ a $94 \%$ com ALA ou MAL. Rhodes e
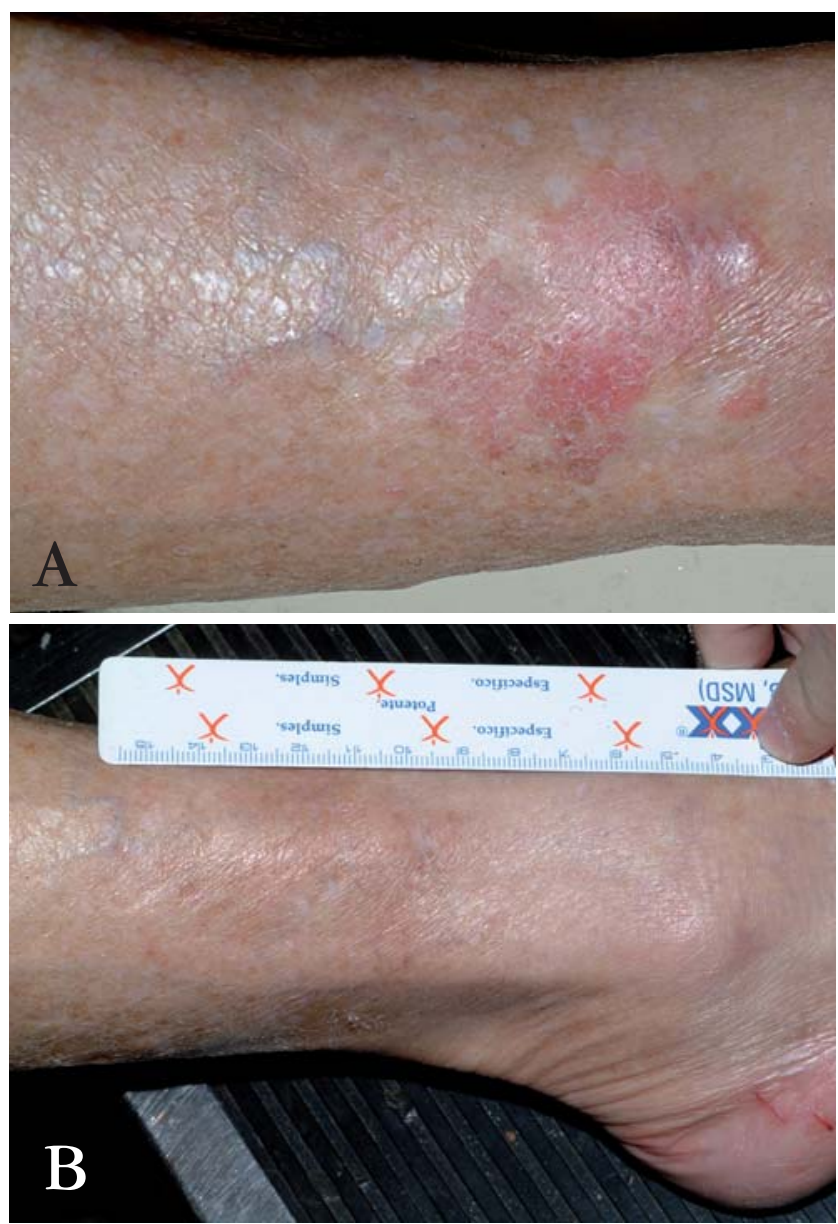

Figura 3: A. Doença de Bowen no membro inferior direito prétratamento; B. Doença de Bowen pós- tratamento com MAL-PDT

( 2 anos de seguimento)

cols, 2007, mostraram a eficácia do MAL - TFD em CBCs nodulares e compararam com a cirurgia convencional. Nos 3 meses iniciais, o índice de cura foi de $91 \%$ para TFD e $98 \%$ para cirurgia. Após 5 anos, houve recorrência de $14 \%$ no grupo de TFD e $4 \%$ no grupo tratado cirurgicamente. Interessante ressaltar que o estudo foi randomizado e prospectivo com análise histopatológica. Após 5 anos, o resultado cosmético final avaliado como bom ou excelente foi de $87 \%$ para o grupo tratado com TFD e $54 \%$ com cirurgia. ${ }^{50}$ Horn e cols e Vinciullo e cols avaliaram o efeito do MAL-TFD em CBCs de difícil tratamento e de alto risco e, mesmo assim, tiveram resultados bons após 3 meses de seguimento: 94\% e 87\% de índice de cura. Após seguimento de 48 e 60 meses, a taxa de recorrência foi de $18 \%$ e $30 \% .46,47$ O uso de ALA para CBCs nodulares mostraram respostas que variam de $50 \%$ a $92 \% .23,24,29,30,45,48,51,52$ A menor resposta pode ser devida à falta de preparo prévio da lesão assim como diferenças nas fontes de luz utilizadas. Além disso, provavelmente, a menor penetração do ALA no tecido pode ter contribuído para a ampla margem de resposta. ${ }^{45,50-52}$ 


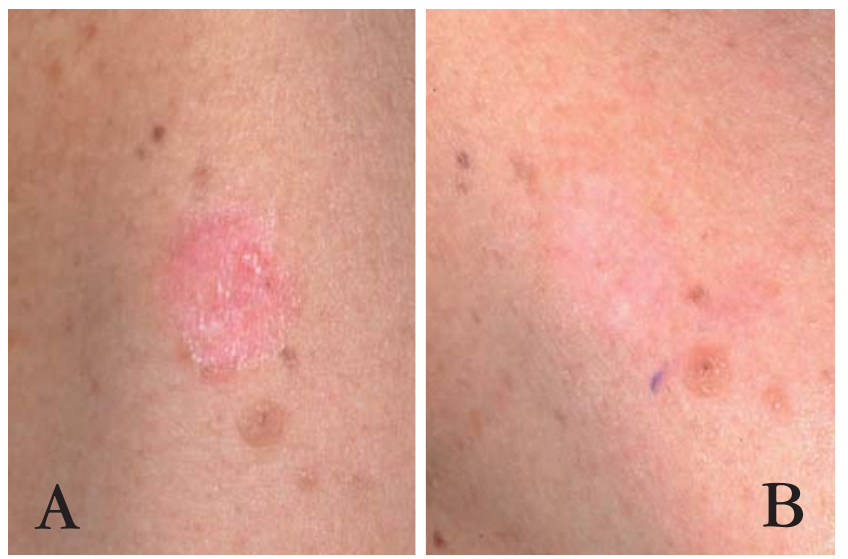

Figura 4: A. Carcinoma Basocelular pré tratamento; B. pós-tratamento com MAL-PDT (seis meses de seguimento)

Sabe-se que MAL pode penetrar até $2 \mathrm{~mm}$ no tecido. Assim, os CBCs nodulares mais finos fora de área de risco apresentam os melhores índices de cura. Desse modo, MAL-TFD deve ser considerada uma opção terapêutica para essas lesões oferecendo elevado índice de cura e excelente resultado cosmético. 27,28,53

\section{INDICAÇÕES NÃO-ONCOLÓGICAS DA TFD NA DERMATOLOGIA}

Os protocolos terapêuticos na TFD em condições cutâneas inflamatórias diferem significativamente daqueles utilizados nos tratamentos de tumores. Enquanto no tratamento de tumores, a destruição celular pela TFD é o principal objetivo, nas dermatoses inflamatórias, a TFD apresenta provável atuação na modulação da função celular. Doses mais baixas tanto de luz quanto de droga fotossensibilizante são usadas nessas condições cutâneas inflamatórias. Entretanto, múltiplas sessões são necessárias para se atingir o efeito terapêutico com poucos efeitos adversos. Cabe salientar que para indicações não-oncológicas na dermatologia, há ainda escassez de estudos clínicos controlados e randomizados, entretanto já existem diversas publicações na Literatura médica, demonstrando a TFD como uma opção terapêutica de valor e segura no tratamento da acne vulgar, psoríase, verrugas virais e esclerodermia localizada. 54

\section{ACNE VULGAR}

Os possíveis mecanismos de ação da TFD na acne são a fotodestruição do $P$. acnes, a redução da produção sebácea e a diminuição da hiperqueratose folicular. ${ }^{55-57}$

Hongcharu e colaboradores ${ }^{57}$ realizaram estudo prospectivo em que demonstrou o efeito do ALATFD em 22 doentes com acne no dorso, dividindo a área tratada em ALA-TFD, somente ALA, somente luz e sem tratamento. Onze pacientes receberam um único tratamento e onze foram tratados 4 vezes. Foi utilizado ALA (20\%) sob oclusão por 3 horas e em seguida a área foi irradiada com luz vermelha $(550-700 \mathrm{~nm}, 150$ $\left.\mathrm{J} \mathrm{cm}^{-2}\right)$. Houve redução significantiva $(\mathrm{p}<0,05) \mathrm{da}$ acne inflamatória 10 semanas após uma sessão e pelo menos 20 semanas após múltiplos tratamentos com TFD. O exame histopatológico mostrou dano citotóxico agudo das glândulas sebáceas. Efeitos adversos encontrados foram: dor, eritema, edema, hiperpigmentação transitória e em alguns casos ocorreram púrpura e erupção acneiforme aguda.

Itoh e colaboradores ${ }^{58}$ avaliaram 23 doentes com acne facial de difícil tratamento submetidos a 1 sessão de ALA-TFD. ALA 20\% em emulsão foi aplicada por 4 horas e em seguida a área foi irradiada com uma lâmpada halógena (600-700 nm, $\left.17 \mathrm{~mW} \mathrm{~cm}{ }^{-2}, 13 \mathrm{~J} \mathrm{~cm}^{-2}\right) \mathrm{O}$ resultado foi uma melhora aparente e redução no aparecimento de novas lesões de acne por mais de 6 meses após o tratamento com TFD.

Hörfelt e colaboradores 59 trataram 30 doentes com acne facial moderada com 2 sessões de MAL-TFD em um estudo randomizado, cego, controlado. Cada hemiface recebeu MAL ou placebo sob oclusão por 3 horas e em seguida as áreas foram irradiadas com luz vermelha não coerente $\left(635 \mathrm{~nm}, 37 \mathrm{~J} \mathrm{~cm}^{2}\right)$. Foi observada redução significantiva $(p<0,05)$ das lesões inflamatórias após MAL-TFD em relação ao grupo placebo, com melhora de 63\% após 6 semanas e de 54\% após 12 semanas.

Wiegell e colaboradores ${ }^{60}$ realizaram estudo comparativo entre ALA-TFD e MAL-TFD em 15 doentes com acne facial moderada. Cada hemiface doente recebeu de forma aleatória $2 \mathrm{~g}$ de ALA 20\% creme e MAL creme sob oclusão por 3 horas. A irradiação foi feita com luz vermelha não coerente $(635 \mathrm{~nm}, 34$ $\mathrm{mW} / \mathrm{cm}^{2}, 37 \mathrm{~J} \mathrm{~cm}^{2}$ ). O resultado observado foi uma melhora de 59\% das lesões, sem diferença estatística entre os dois tratamentos. ALA-TFD apresentou efeitos adversos mais prolongados e intensos após o tratamento.

Os estudos demonstram o efeito terapêutico benéfico da TFD na acne inflamatória com as vantagens de não tratar-se de um tratamento sistêmico, com melhor adesão ao tratamento em contrapartida ao uso prolongado de antibióticos, que apresenta o risco de resistência bacteriana. Além disso, a TFD deve ser lembrada como uma opção terapêutica no caso de contra-indicação à isotretinoína sistêmica. As principais limitações dessa modalidade terapêutica incluem: padronização dos parâmetros de tratamento (tempo de incubação, tipo de luz, número de sessões, manutenção), custo elevado e particularmente o manejo da dor a fim de otimizar os resultados e minimizar os efeitos adversos. 


\section{VERRUGAS VIRAIS}

Verrugas vulgares de mãos e pés, verrugas planas e as verrugas genitais (condiloma acuminado) são doenças cutâneas comuns induzidas pelo papiloma vírus humanos (HPV). Na prática clínica, é freqüente observarmos elevada taxa de recorrência mesmo após remoção cirúrgica ou uso de drogas citotóxicas. Na Literatura, há estudos demonstrando bons resultados da TFD no tratamento de verrugas recalcitrantes.61-65 O mecanismo de ação envolve o acúmulo de PpIX induzido por ALA nas células epidérmicas que estão rapidamente proliferando ${ }^{66,67}$ e as propriedades virucidas de ALA-TFD. 68

\section{VERRUGA VULGAR}

Os primeiros estudos realizados por Kennedy e colaboradores $^{69}$, e Amman e colaboradores ${ }^{70}$ não obtiveram sucesso no tratamento de verrugas vulgares com ALA-TFD. A provável causa da falha terapêutica foi a ausência de preparo prévio das lesões. Assim, a hiperqueratose proeminente das verrugas impediu a penetração cutânea eficiente do ALA. Smetana ${ }^{68}$ e colaboradores tentaram aumentar a efetividade do tratamento através do uso de EDTA (2\%) e DMSO (2\%) para aumentar a penetração de ALA. Paciente transplantado renal que apresentava verrugas vulgares disseminadas foi tratado com sucesso e sem recidiva no seguimento de 2 anos.

Stender e colaboradores ${ }^{62}$ realizaram estudo piloto em que foram comparadas as fontes de luz visível, luz azul e luz vermelha com ALA-TFD e demonstraram que a luz visível foi mais efetiva seguida da luz vermelha e da luz azul. As taxas de resposta completa foram $73 \%, 42 \%$ e $28 \%$ respectivamente (projetor de slide com comprimentos de onda diferentes; dose total $40 \mathrm{~J} / \mathrm{cm}^{2}$, período de incubação 5 horas). Posteriormente, o mesmo grupo publicou um estudo duplo cego randomizado com 45 pacientes comparando o uso de ALA-TFD e placebo em verrugas recalcitrantes das mãos e pés. ${ }^{63} \mathrm{~A}$ taxa de resposta completa foi de 56\% (Waldmann PDT I $200,590-700 \mathrm{~nm}$, dose total $70 \mathrm{~J} / \mathrm{cm}^{2}$, período de incubação 4 horas), que foi estatisticamente superior em relação ao placebo.

Em 2001, Fabbrocini e colaboradores ${ }^{64}$ demonstraram uma taxa de resposta completa de $75 \%$ (lâmpada de tungstênio $400-700 \mathrm{~nm}$; dose total 50 $\mathrm{J} / \mathrm{cm}^{2}$, período de incubação 5 horas). O uso de queratolíticos e a curetagem superficial prévia possivelmente contribuíram para os resultados favoráveis obtidos no estudo.

Os parâmetros de irradiância, comprimento de onda, e dose total de energia ainda não foram estabelecidos. Para fontes de luz a laser, as doses utilizadas foram de $60-250 \mathrm{~J} / \mathrm{cm}^{2}$; enquanto para fontes de luz de amplo espectro, de $3-540 \mathrm{~J} / \mathrm{cm}^{2} .{ }^{71}$
Dessa forma, a TFD tópica deve ser lembrada no tratamento de verrugas virais recalcitrantes, particularmente quando o local, tamanho ou número de lesões limita o uso das terapias convencionais. As vantagens incluem: toxicidade sistêmica mínima, tratamento não invasivo, e bom resultado cosmético. As limitações referem-se ao custo elevado, ao tempo dispendido e o manejo da dor.

\section{VERRUGAS GENITAIS}

A maioria das modalidades terapêuticas destrutivas dos condilomas anogenitais como eletrocauterização ou vaporização com laser de $\mathrm{CO}_{2}$ destroem apenas a porção visível das verrugas, enquanto as lesões subclínicas persistem e causam freqüentemente a recorrência das lesões. ALA-TFD apresenta então como vantagem a destruição seletiva dessas lesões subclínicas, auxiliando a reduzir a taxa elevada de recorrência.

Fehr e colaboradores ${ }^{66}$ estudaram a fluorescência de PpIX após aplicação de ALA em condiloma acuminado de 22 pacientes. Três a seis horas após, foi observado uma fluorescência distribuída de forma homogênea na epiderme. Em estudo de série de casos realizado por Stefanaki e colaboradores 72 em 12 pacientes homens com condiloma acuminado tratados com TFD (ALA $6-11$ horas, 400-800 nm,70 -100 $\left.\mathrm{J} / \mathrm{cm}^{2}, 70 \mathrm{mw} \mathrm{cm}{ }^{-2}\right), 73 \%$ dos pacientes apresentaram resposta completa.

Wang e colaboradores realizaram um estudo grande aberto com 164 pacientes em que 95\% das lesões melhoraram com uma a quatro sessões de ALATFD (ALA 3 horas, $630 \mathrm{~nm}, 100 \mathrm{~J} / \mathrm{cm}^{-2}, 100 \mathrm{~mW} \mathrm{~cm}{ }^{-2}$ ). 73 No seguimento de 6-24 meses, apenas 5\% das lesões recidivaram.

Resultados menos favoráveis com ALA-TFD (ALA 5 horas, $630 \mathrm{~nm}, 37 \mathrm{~J} / \mathrm{cm}^{-2}, 68 \mathrm{~mW} \mathrm{~cm}^{-2}$ ) foram observados em 9 homens com condiloma genital resistentes às terapias convencionais com melhora apenas em 3 pacientes, após 4 sessões. ${ }^{74}$

A TFD tópica pode ser considerada como uma opção terapêutica para os pacientes com verrugas genitais. Talvez a sua combinação com os tratamentos ablativos convencionais contribua para a redução da recorrência das lesões em virtude da destruição seletiva das lesões subclínicas pela TFD.

\section{MORFÉIA}

A morféia consiste numa condição de reação inflamatória crônica da pele em que após uma fase inflamatória ocorre a esclerose circunscrita da pele. Apesar do prognóstico favorável na maioria dos casos, lesões disseminadas podem levar a contrações de articulações e imobilização. 
Karrer e colaboradores realizaram um estudo de observação clínica com 10 pacientes que apresentavam lesões de morféia resistentes ao tratamento com banho de PUVA e terapias locais. ${ }^{75}$ Foram submetidos a uma média de $26 \pm 8$ sessões de ALA-TFD (ALA gel 3\% por 6 horas, luz de amplo espectro PDT $1200 \mathrm{~L}, 40 \mathrm{~mW}$ $\mathrm{cm}^{-2}, 10 \mathrm{~J} / \mathrm{cm}^{-2}$ ) semanais ou bissemanais. Foi feita a avaliação do grau de esclerose através de uma pontuação clínica e do uso de um durômetro. Em todos os pacientes, foi observada melhora significativa dos dois parâmetros no final do tratamento. Como efeito adverso, foi relatada discreta hiperpigmentação na área tratada. No seguimento de dois anos, não houve recorrência ou progressão das lesões, entretanto alguns pacientes desenvolveram lesões novas em áreas não tratadas com TFD. O mecanismo de ação proposto pelo mesmo grupo parece estar relacionado à indução de metaloproteinases da matriz (MMP-1 e MMP-3) pelos fibroblastos após a TFD. ${ }^{76}$ Além disso, a liberação de IL-1 pelos queratínócitos após a TFD induz através de uma ação parácrina a produção de metaloproteinases pelos fibroblastos dérmicos. ${ }^{77}$

Mais recentemente tem sido desenvolvidos estudas da aplicação da TFD em outras patologias cutâneas como fotoenvelhecimento, micose fungóide e sarcoma de kaposi.

\section{FOTOREJUVENESCIMENTO}

Devido ao aumento pela procura por procedimentos menos invasivos, porém eficazes, no processo de rejuvenescimento, novos processos e técnicas nãoablativas têm sido empregadas. Vários estudos recentes mostram melhora da pele fotodanificada e neocolagênese com o uso de lasers vasculares, infra-vermelho, luz intensa pulsada, radiofreqüência não-ablativa e resurfacing fracionado. Um dos métodos mais recentes introduzido na terapêutica dermatológica é o processo de fotorejuvenescimento com a terapia fotodinâmica. Muitos estudos foram feitos com uso de fotossensibilizante e LIP ou "pulsed dye laser" (PDL). ${ }^{78}$ Até hoje, os mecanismos moleculares que expliquem o rejuvenescimento com TFD estão muito longe de serem conhecidos. A compreensão dos mecanismos envolvidos na TFD assim como as interações luzagente fotossensibilizante - tecido são absolutamente necessárias para a melhor seleção dos pacientes assim como a indicação da TFD como tratamento do envelhecimento da pele.

A partir da observação de que o efeito da TFD na face mostrava um resultado cosmético satisfatório, a técnica é utilizada com tal propósito, havendo melhora da textura da pele e considerada, hoje, uma potencial terapêutica no fotorejuvenescimento. Nesse sentido, vários investigadores iniciaram algumas tentativas terapêuticas para tornar a TFD-ALA mais atrati- va à cosmética. Touma et al, reduziram o tempo de aplicação do ALA para 1, 2 e 3 horas associado ao mesmo protocolo de iluminação com luz azul.79 Os autores observaram que o tempo de incubação reduzido mostrava-se tão eficaz quanto o protocolo original de 14 a 18 horas. Em 2002, Ruiz-Rodriguez et al, introduziram o termo fotorejuvenescimento fotodinâmico. ${ }^{80}$ Os autores avaliaram a combinação de LIP associada ao 5-ALA ( formulação em creme $20 \%$ ) no tratamento da pele da face com QAs e sinais de envelhecimento. Após duas sessões de tratamento, com intervalo de 30 dias, os autores observaram 91\% de cura das QAs e excelente efeito cosmético global da face. Gold usou a combinação de LIP e ALA em período de incubação curto (entre 30 e 60 minutos, 3 tratamentos com intervalo mensal e observou melhora de $90 \%$ das rugas peri-oculares, $100 \%$ da textura, $90 \%$ da pigmentação, $70 \%$ das tealangectasias e $83 \%$ de cura das QAs. ${ }^{81}$ Avram et al, observaram 68\% de cura das QAs, 55\% de melhora das telangectasias faciais, $48 \%$ da pigmentação e $25 \%$ da textura, após uma única sessão de LIP e ALA incubado por 1 hora. ${ }^{82}$

Em 2005, Dover et al observaram eficácia superior da LIP-ALA sobre LIP isolada em um estudo prospectivo, randomizado. 83 Os resultados mostraram maior grau de melhora do envelhecimento global no lado tratado com LIP-ALA em relação ao outro lado tratado com LIP isolada. Os autores também relataram efeitos adversos e tolerância ao tratamento semelhantes em ambos os lados. Em outro estudo piloto, Torezan et al estudaram o efeito da LIP associada ao ALA incubado por 2 horas sob oclusão através de histopatologia antes e após um único tratamento. ${ }^{84}$ Os pacientes foram submetidos ao tratamento com LIP ( Photoderm ESC-Sharplan, USA) com filtro de corte $615 \mathrm{~nm}$, fluência de $40 \mathrm{~J} / \mathrm{cm}^{2}$ pulso triplo $7 \mathrm{~ms}$ e intervalo entre pulsos de $20 \mathrm{~ms}$. Os pacientes recebiam 1 passada em toda face e 2 passadas adicionais nas áreas onde as QAs eram mais evidentes. O tempo de recuperação foi de até 30 dias, havendo melhora do envelhecimento global da face e cura clínica de $100 \%$ das QAs. A avaliação histopatológica mostrou diminuição da atipia dos queratinócitos, reorganização e síntese de colágeno na derme superficial, porém nenhum efeito foi observado na elastose solar. Interessante notar, que muitas QAs desse estudo começaram a recidivar pouco depois da conclusão do mesmo, que foi de 6 meses (intervalo entre as biópsias).

Mamur et al, em 2005, estudaram as alterações do colágeno com microscopia eletrônica, em pacientes submetidos a dois tratamentos com ALA-LIP ou LIP isoladamente. ${ }^{85}$ Nesse estudo foi observado um aumento de colágeno tipo I em ambos os grupos, porém, mais intenso no grupo previamente tratado com ALA. 
Em 2007, Zane et al avaliaram o uso do MAL (cloridrato de metilaminolevulinato) e luz contínua vermelha (LED $635 \mathrm{~nm}$ ) no tratamento da pele fotodanificada. ${ }^{86}$ Após 2 sessões, houve cura das QAs de 89\% e redução considerável do grau de fotodano dos pacientes. A avaliação ecográfica da pele mostrou significativo aumento da espessura da derme. Contudo, as telangectasias, hiperpigmentações e rugas profundas não mostraram resposta significativa. ${ }^{87}$

Até o presente momento temos que considerar o processo de fotorejuvenescimento com TFD um tratamento off-label. O efeito de rejuvenescimento induzido pela TFD é secundário e deve ser empregado
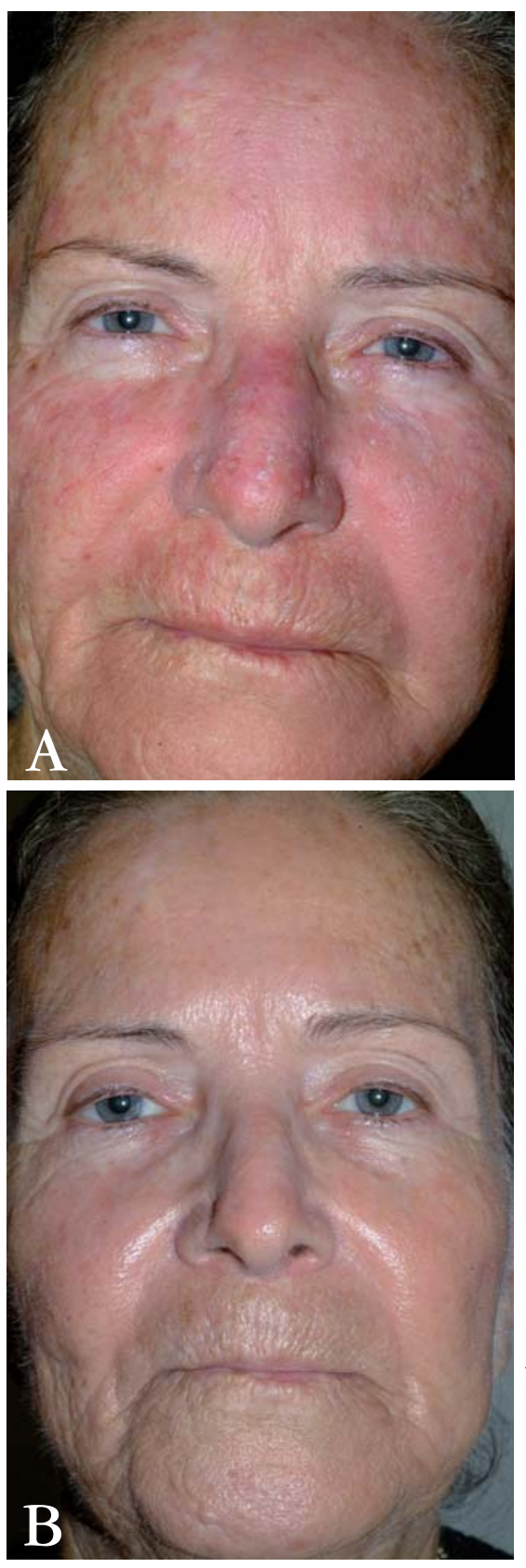

Figura 5

A. TFD e fotorejuvenescimento pré-tratamento B. Após três sessões de MAL-PDT para pacientes com múltiplas QAs na face. (Figura 5) Para haver boa resposta, deve-se esperar reação típica de TFD, ou seja, eritema, edema e descamação. Após o sucesso do tratamento inicial, outras técnicas podem ser combinadas como resurfacing fracionado, ablativo, peelings químicos e Luz intensa pulsada.

\section{MICOSE FUNGÓIDE}

O uso da TFD no tratamento das lesões iniciais em placas de MF parece mostrar bons resultados com uso de fotossensibilizantes sistêmicos. A droga HPD é capaz de fotossensibilizar linfócitos de pacientes portadores de MF e de inibir a sua proliferação, semelhante ao que ocorre com PUVA. ${ }^{16} \mathrm{O}$ uso de drogas tópicas como ALA e MAL parece mostrar resultados variáveis após múltiplas sessões. ${ }^{87}$ Novos estudos são necessários para estabelecer a real participação da TFD no tratamento da MF.

\section{SARCOMA DE KAPOSI}

O uso de TFD sistêmica com Porfirmer sódico mostrou eficácia no tratamento de lesões superficiais e nodulares de SK com poucos efeitos adversos e excelente cosmética final. 88 Os protocolos, porém, variam e podem induzir bolhas, edema, cicatrizes, hiperpigmentação e sintomas sistêmicos decorrentes da intensa agressão aos tumores. Trata-se de um potencial terapêutico pois, em geral, as respostas são semelhantes aos outros métodos já usados no tratamento do SK. 89,90

\section{CONSIDERAÇÕES FINAIS}

Vimos, do exposto acima, uma abordagem geral da TFD na dermatologia, particularmente na oncologia cutânea. Nos últimos 5 anos, o método passou, de investigacional, para realidade na terapêutica dermatológica.

Para a obtenção dos melhores resultados, faz-se necessário seguir corretamente os passos na realização do método. Assim, utilizando os protocolos já publicados e aqui apresentados, fontes de luz corretas e, o mais importante- a correta indicação da TFD pode-se chegar aos índices de cura mais elevados e a resultados cosméticos excelentes, como provam todas as publicações de TFD. Recentemente, a TFD com MAL foi utilizada em pacientes portadores de queilite actinica, havendo resposta completa em $47 \%$ e reposta parcial em outros $47 \% .91$ 


\section{REFERÊNCIAS}

1. Szeimies RM, Matheson RT, Davis SA, Bhatia AC, Frambach Y, Klövekorn W, et al. Topical methyl aminolevulinate photodynamic therapy using red light-emitting diode light for multiple actinic keratoses: a randomized study. Dermatol Surg. 2009;35:586-92.

2. Szeimies RM, Morton CA, Sidoroff A, Braathen LR. Photodynamic therapy for non-melanoma skin cancer. Acta Derm Venereol. 2005;85:483-90.

3. Karrer S, Szeimies RM, Hohenleutner U, Landthaler M. Role of lasers and photodynamic therapy in the treatment of cutaneous malignancy. Am J Clin Dermatol. 2001;2:229-37.

4. Daniell MD, Hill JS. A history of photodynamic therapy. Aust N Z J Surg. 1991;61:340-8.

5. Spikes JD. The origin and meaning of the term photodynamic ( as used in "photodynamic therapy" for example). J Photochem Photobio B. 1991;9:369-74.

6. Daniell MD, Hill JS. A history of photodynamic therapy. Aust N Z J Surg. 1991;61:340-8.

7. Raab O. Uber die Wirkung fluoreszierenden Stoffe auf Infusorien. Z Biol. 1900;39:524-46.

8. Von Tappeiner H, Jodlbauer A. Ueber die Wirkung der photodynamichen (fluoresciereden) Sotffe auf Protozoan und Enzime. Dtsch Arch Klin Med. 1904;80:427-87.

9. Lui $\mathrm{H}$, Bissonnette R. Photodynamic therapy. In: Goldman MP, Fitzpatrick RE. Cutaneous laser surgery. 2 ed. St. Louis: Mosby; 1999. p.437-58.

10. Nelson JS, McCullough JL, Berns MW. Principles and applications of photodynamic therapy in dermatology. In: Ardnt KA, Dover JS, Olbright SM. Lasers in cutaneous and aesthetic surgery. Philadelphia: Lippincot-Raven; 1997. p.349-82.

11. Dougherty TJ. Photoirradiation therapy for the treatment of malignant tumors. Cancer Res. 1978;38:2628-35.

12. Li JH, Guo ZH, Jin ML, Zhao FY, Cai WM, Gao ML, et al. Photodynamic therapy in the treatment of malignant tumors: an analysis of 540 cases. J Photochem Photobiol B. 1990;6:149-55.

13. Kennedy JC, Pottier RH, Pross DC. Photodynamic therapy with endogenous protoporphyrin IX: basic principles and present clinical experience. J Photochem Photobiol B. 1990;6:143-8.

14. Kennedy JC, Pottier RH. Endogenous protoporphyrin IX: a clinical useful photosensitizer for photodynamic therapy. J Photochem Photobiol B. 1992;14:275-92.

15. Calzavara-Pinton PG, Venturini M, Sala R. Photodynamic therapy: update 2006. Part 1: Photochemistry and photobiology. J Eur Acad Dermatol Venereol. 2007;21:293-302.

16. Kalka K, Merk H, Mukhtar H. Photodynamic therapy in dermatology J Am Acad Dermatol. 2000;42:389-413.

17. Torezan LA. Terapia fotodinâmica em dermatologia. In: Laser em dermatologia. 2 ed. São Paulo: Editora Roca Ltda; 2009. p.187-94.

18. Szeimies RM, Karrer S, Sauerwald A, Landthaler M. Photodynamic therapy with topical application of 5 -aminolevulinic acid in the treatment of actinic keratoses: an initial clinical study. Dermatology. 1996;192:246-51.
19. Babilas P, Karrer S, Sidoroff A, Lanthaler M, Szeimies RM. Photodynamic therapy in dermatology- an update. Photodermatol Photochem Photomed. 2005;21:142-9.

20. Wolf P, Rieger E, Kerl H. Topical photodynamic therapy with endogenous porphyrins after application of 5- aminolevunic acid. An alternative treatment modality for solar keratoses, superficial squamous cell carcinomas and basal cell carcinomas? J Am Acad Dermatol. 1993;28:17-21.

21. Orenstein A, Kostenich G, Roitman L, Tsur H, Katanick. D, Kopolovic J, et al. Photodynamic therapy of malignant lesions of the skin mediated by topical application of 5- ALA in combination with DMSO and EDTA. Lasers Life Sci. 1996;7:49-57.

22. Nestor MS, Gold MH, Kauvar ANB, Taub AF, Geronemus RG, Ritvo EC, et al. The use of phodynamic therapy in dermatology: results of a consensus conference. J Drugs Dermatol. 2006;5:140-54.

23. Svanberg K, Andersson T, Killander D, Wang I, Stenram $\mathrm{U}$, Andersson-Engels S, et al. Photodynamic therapy of non-melanoma malignant tumors of the skin using topical 5-ALA and laser irradiation. BR J Dermatol. 1994;130:743-51.

24. Cairduff F, Stringer MR, Hudson EJ, Ash DV, Brown SB. Superficial photodynamic therapy with 5- ALA for superficial primary and secondary skin cancer. Br J Cancer. 1994;69:605-8.

25. Szeimies RM, Karrer S, Radakovic-Fijan S, Tanew A, Calzavara-Pinton P, Zane C, et al. Photodynamic therapy using methyl aminolevelinate compared with cryotherapy for actinic keratosis: a prospective, randomized study. J Am Acad Dermatol 2002;47:258-62.

26. Pariser D, Lowe N, Stewart DM, Jarratt MT, Lucky AW, Pariser RJ, et al. Photodynamic therapy with topical methyl aminolevulinate for actinic keratosis: results of a prospective randomized multicenter trial. J Am Acad Dermatol. 2003; 48:227-32.

27. Angell-Petersen E, Sorensen R, Warloe T, Soler AM, Moan J, Peng Q, et al. Porphyrin formation in actinic keratosis and basal cell carcinoma after topical application of methyl 5-aminolevulinate. J Invest Dermatol. 2006;126: 265-71.

28. Braathen L, Szeimies RM, Basset-Seguin N, Bissonnette R, Foley P, Pariser D, et al. Guidelines on the use of photodynamic therapy for non melanoma skin cancer: an international consensus. J Am Acad Dermatol. 2007;56:12543.

29. Fijan S, Honigsman H, Ortel B. Photodynamic therapy of epithelial skin tumors using delta-aminolevulinic acid and desferroxamine. Br J Dermatol. 1995;133:282-8.

30. Fink-Puches R, Wulf $P$. Long term follow-up and histological changes of superficial non-melanoma skin cancers treated with topical delta-aminolevulinic acid photodynamic therapy. Arch Dermatol 1998;134:821-6.

31. Martin A, Tope WD, Grevelink JM, Starr JC, Fewkes JL, Flotte TJ, et al. Lack of selectivity of protoporphyrin IX fluorescence for basal cell carcinoma after topical application of 5-ALA: implicarions for photodynamic treatment. Arch Dermatol Res. 1995;287:665-74.

32. Rhodes LE, Tsoukas MM, Anderson RR, Lollias N. Iontophoretic delivery of ALA provides a quantitative 
model for ALA pharmakokinetics and PpIX phototoxicity in human skin. J Invest Dermatol. 1997;108:87-91.

33. Kessel D, Luo Y. Delayed oxidative photodamage induced by photodynamic therapy. Photochem Photobiol. 1996;64:601-4.

34. Piacquadio DJ, Chen DM, Farber HF, Fowler JF Jr, Glazer SD, Goodman JJ. Photodynamic therapy with aminolevulinic topical solution and visible blue light in the treatment of multiples actinic keratoses of the face and scalp: investigator-blinded, phase 3, muticenter trials. Arch Dermatol. 2004;140:41-6.

35. Touma D, Yaar M, Whitehead S, Konnikov N, Gilchrest BA. A trial of short incubation, broad-area photodynamic therapy for facial actinic keratosis and diffuse photodamage. Arch Dermatol 2004;140:33-40.

36. Alexiades-Armenakas MR, Geronemus RG. Lasermediated photodynamic therapy of actinic keratoses. Arch Dermatol. 2003;139:1313-20.

37. Freeman M, Vinciullo C, Francis D, Spelman L, Nguyen $\mathrm{R}$, Fergin $\mathrm{P}$ et al. A comparison of photodynamic therapy using topical methyl aminolevulinate with single cicle cryotherapy in patients with actinic keratosis: a prospective, randomized study. J Dermatol Treat. 2003;14:99-106.

38. Tarstedt M, Rosdahl I, Berne B, Svanberg K, Wennberg AM. A randomized multicenter study to compare two treatment regimens of topical methyl aminolevulinate PDT in actinic keratosis of the face and scalp. Acta Derm Venereol 2005;85:424-8.

39. Morton C, Horn M, Lehman J, Tack B, Bedane C, Tijoe $\mathrm{M}$, et al. A 24-month update of a placebo controlled European study comparing MAL-PDT with cryotherapy and 5-fluorouracil in patients with Bowen's disease. J Eur Acad Dermatol Venereol. 2005;19(Suppl 2):237-8.

40. Salim A, Lehman JA, McColl JH, Chapman R, Morton CA. Randomized comparison of photodynamic therapy with topical 5-fluorouracil in Bowen's disease. Br J Dermatol. 2003;148:539-43.

41. Morton CA, Whitehurst C, Moseley $\mathrm{H}$, McColl JH, Moore JV, Mackie RM. Comparison of photodynamic therapy with cryotherapy in the treatment of Bowen's disease. Br J Dermatol. 1996;135:766-71.

42. Morton CA. Methyl aminolevulinate: actinic keratoses and bowen's disease. Dermatol Clin. 2007;25:81-7.

43. Wennberg AM, Lindholm LE, Alpsten M, Larko O. Treatment of superficial basal cell carcinomas using topically applied delta-aminolevulinic acid and a filtered xenon lamp. Arch Dermatol Res. 1996;288:561-4.

44. Basset-Seguin N, Ibbotson S, Emtestam L, Tarstedt M, Morton CA, Maroti M, et al. MAL-PDT versus cryotherapy in primary sBCC: results of a 36 months follow-up. J Eur Acad Dermatol Venereol. 2005; 19(supp2) 237.

45. Soler AM, Warloe T, Berner A, Giercksky KE. A follow-up study of the recurrence and cosmesis in completely responding superficial and nodular basal cell carcinomas treated with methyl 5-aminolevulinate-based photodynamic therapy alone and with prior curettage. Br J Dermatol. 2001;145:467-71.

46. Horn M, Wolf P, Wulf HC, Warloe T, Fritsch C, Rhodes LE, et al. Topical methyl aminolevulinate photodynamic therapy in patients with basal cell carcinoma prone to complications and poor cosmetic outcome with conventional therapy. Br J Dermatol. 2003;149:1242-9.

47. Viciullo C, Elliott T, Gebauer K, Spelman L, Nguyen R. MAL-PDT in patients with basal cell carcinomas: results of an Australian multicenter study. Poster presented to the international Skin Cancer Conference, Zurich, Switzerland, July 22-24, 2004.

48. Hurlimann AF, Hanggi G, Panizzon RG. Photodynamic therapy of superficial basal cell carcinomas using 5-ALA in a nanocoloid lotion. Dermatology. 1998;197:248-54.

49. Calzavara-Pinton PG. Repetitive photodynamic therapy with topical delta-aminolevulinic acid as an appropriate approach to the routine treatment of superficial non-melanoma skin tumours. J Photochem Photobiol B. $1995 ; 29: 53-7$.

50. Rhodes LE, de Rie MA, Leifsdottir R, Yu RC, Bachmann I, Goulden V, et al. Five year follow-up of a radomized, prospective trial of topical methyl aminolevulinate photodynamic therapy vs surgery for nodular basal cell carcinoma. Arch Dermatol. 2007;143:1131- 6.

51. Soler AM, Warloe T, Tausjo J, Berner A. Photodynamic therapy by topical aminolevulinic acid, dimethyl sulphoxide and curettage in nodular basal cell carcinoma: o one year follow-up study. Acta Derm Venereol. 1999;79:204-6.

52. Thissen MR, Schroeter CA, Neumann HA. Photodynamic therapy with delta-aminolevulinic acid for nodular basal cell carcinomas using a prior debulking technique. Br J Dermatol. 2000;142:338-9.

53. Peng Q, Soler AM, Warloe T, Nesland JM, Giercksky. Selective distribution of porphyrins in thick basal cell carcinoma atr topical application of methyl 5-aminolevulinate. J Photochem Photobiol B. 2001;62:140-5.

54. Babilas P, Landthaler M, Szeimies RM. Photodynamic therapy in dermatology. Eur J Dermatol. 2006;16:340-48.

55. Pollock B, Turner D, Stringer MR, Bojar RA, Goulden V, Stables GI et al. Topical aminolaevulinic acid-photodynamic therapy for the treatment of acne vulgaris: a study of clinical efficacy and mechanism of action. Br J Dermatol. 2004;151:616-22.

56. Divaris DX, Kennedy JC, Pottier RH. Phototoxic damage to sebaceous glands and hair follicles of mice after systemic administration of 5-aminolevulinic acid correlates with localized protoporphyrin IX fluorescence. Am J Pathol. 1990;136:891-7.

57. Hongcharu W, Taylor CR, Chang Y, Aghassi D, Suthamjariya K, Anderson RR. Topical ALA-photodynamic therapy for the treatment of acne vulgaris. J Invest Dermatol. 2000;115:183-92.

58. Itoh Y, Ninomiya Y, Tajima S, Ishibashi A. Photodynamic therapy of acne vulgaris with topical delta-aminolaevulinic acid and incoherent light in Japanese patients. Br J Dermatol. 2001;144:575-9.

59. Hörfelt C, Funk J, Frohm-Nilsson M, Wiegleb Edström D, Wennberg AM. Topical methyl aminolaevulinate photodynamic therapy for treatment of facial acne vulgaris: results of a randomized, controlled study. Br J Dermatol. 2006;155:608-13.

60. Wiegell SR, Wulf HC. Photodynamic therapy of acne vulgaris using 5-aminolevulinic acid versus methyl aminolevulinate. J Am Acad Dermatol. 2006;54:647-51.

61. Frank RGJ, Bos JD. Photodynamic therapy for condylomata acuminata with local application of 5-aminolae 
vulinic acid. Genitourin Med. 1996;72:70-1.

62. Stender IM, Lock Anderson J, Wulf HC. Recalcitrant hand and foot warts successfully treated with photodynamic therapy with topical 5-aminolevulinic acid. A pilot study. Clin Exp Dermatol. 1999;24:154-9.

63. Stender IM, Na R, Fogh H, Gluud C, Wulf HC. Photodynamic therapy with 5-aminolaevulinic or placebo for recalcitrant foot and hand warts: randomized double-blind Trial. Lancet. 2000;355:963-6.

64. Fabbrocini G, Constanzo MP, Ricardo AM, Quarto M, Colasanti A, Roberti G, et al. Photodynamic therapy with topical \%o-aminolevulinic acid for the treatment of plantar warts. J Photochem Photobiol B. 2001;61:30-34.

65. Schroeter CA, Pleunis J, van Nispen tot Pannerden C, et al. Photodynamic therapy: new treatment for therapy resistant plantar warts. Dermatol Surg. 2005; 3I: 71-75.

66. Fehr MK, Chapman CF, Krasieva T, Reineke T, Neumann HA. Selective photosensitizer distribution in vulvar condylomata acuminatum after topical application of 5-aminolevulinic acid. Am J Obstet Gynecol. 1996;174:951-7.

67. Ross EV, Romero R, Kollias N, Crum C, Anderson RR. Selectivity of protoporphyrin IX fluorescence for condylomata after topical application of 5-aminolaevulinic acid: implications for photodynamic treatment. Br J Dermatol 1997; 137:736-42.

68. Smetana Z, Malik Z, Orenstein A, Mendelson E, Ben-Hur E. Treatment of viral infection with 5-amino laevulinic acid and light. Lasers Surg Med. 1997;21:351-8.

69. Kennedy JC, Pottier RH, Pross DC. Photodynamic therapy with endogenous protoporphyrin IX: basic principles and present clinical experience. J Photochem Photobiol B. 1990;6:143-8.

70. Ammann R, Hunziker T, Braathen LR. Topical photodynamic therapy in verrucae. A pilot study. Dermatology. 1995;191:346-7.

71. Peng Q, Warloe T, Berg C, Moan J, Kongshaug M, Giercksky KE, et al. 5-Aminolevulinic acid-based photodynamic therapy: clinical research and future challenges. Cancer. 1997; 79:2282-308.

72. Stefanaki IM, Georgiou S, Themelis GC, Vazgiouraki $\mathrm{EM}$, Tosca $\mathrm{AD}$. In vivo fluorescence kinetics and photodynamic therapy in condylomata acuminate. Br J Dermatol. 2003;149:972-6.

73. Wang XL, Wang HW, Wang HS, Xu SZ, Liao KH, Hillemanns P. Topical 5-aminolevulinic acid-photodynamic therapy for the treatment of urethral condylomata acuminate. Br J Dermatol. 2004;151:880-5.

74. Herzinger T, Wienecke R, Weisenseel P, Borelli C, Berking C, Degitz K. Photodynamic therapy of genital condylomata in men. Clin Exp Dermatol. 2006;31:51-3.

75. Karrer S, Abels C, Landthaler M, Szeimies RM. Topical photodynamic therapy for localized scleroderma. Acta Derm Venereol. 2000;80:26-7.

76. Karrer S, Bosserhoff AK, Weiderer P, Szeimies RM. Influence of 5-aminolevulinic acid and red light on collagen metabolism of human dermal fibroblasts. J Invest Dermatol. 2003;120:325-31.

77. Karrer S, Bosserhoff AK, Weiderer P, Landthaler M,
Szeimies RM. Keratinocyte-derived cytokines after photodynamic therapy and their paracrine induction of metalloproteinases in fibroblasts. $\mathrm{Br} \mathrm{J}$ Dermatol. 2004;151:776-83.

78. Ruiz-Rodriguez R, López-Rodriguez L. Non-ablative skin resurfacing: the role of PDT. J Drugs Dermatol. 2006;5:756-62.

79. Touma D, Yaar M, Whitehead S, Konnikov N, Gilchrest BA. A trial of short incubation, broad area photodynamic therapy for facial actinic keratoses and diffuse photodamage. Arch Dermatol. 2004;140:33-40.

80. Ruiz-Rodriguez R, Sanz-Sanchez T, Corbodo S. Photodynamic photorejuvenation. Dermatol Surg. 2002;28:742-4.

81. Gold MH. Intense pulsed light therapy for photorejuvenation enhanced with $20 \%$ aminolevulinic acid photodynamic therapy. Lasers Med Surg. 2003;15:S 47.

82. Avram D, Goldman MP. Effectiveness and safety of ALA-IPL in treating actinic keratoses and photodamage. J Drugs Dermatol. 2004;3:S36-9.

83. Dover JS, Bhatia AC, Stewart B, Ardnt KA. Topical 5-ALA combined with intense pulsed light in the treatment of photoaging. Arch Dermatol. 2005;141:1247-52.

84. Torezan LA, Osorio N, Festa-Neto C, Soto MN. Photodynamic photorejuvenation of the skin using 5-ALA and intense pulsed light: clinical and histological evaluation. Lasers Surg Med Suppl. 2005;17: 93.

85. Marmur ES, Phelps R, Goldberg DJ. Utrastructural changes seen after ALA-IPL photorejuvenation: a pilot study. J Cosmet Laser Ther. 2005;7:21-4.

86. Zane C, Capezzera R, Sala R, Ventrini M, CalzavaraPinton PG. Clinical and echogtaphical analysis of photodynamic therapy using methylaminolevulinate as sensitizer in the treatment of photodamage facial skin. Lasers Surg Med. 2007;39:203-9.

87. Wolf P, Fink-Puches R, Cerroni L, Kerl H. PDT for mycosis fungoides after topical photosensitization with 5- ALA. J Am Acad Dermatol. 1994;31:678-80.

88. Schweiter VG. PDT for the treatment of head and neck câncer. Otolaryngol Head Neck Surg. 1990;102:225-32.

89. Gill PS, Rarick M, McCuthan JA, Slater L, Parker B, Muchmore E, et al. Systemic treatment of AIDS- related Kaposi`s sarcoma: results of a randomized trial. AM J Med. 1991;90:427-33.

90. Hebeda KM, Huizing MT, Brouwer PA, van der Meulen FW, Hulsebosch HJ, Reiss P, et al. PDT in AIDS -related cutaneous Kaposi's sarcoma. J Acquir Immune Defic Syndr Hum Retrovirol. 1995; 10:61-70.

91. Berking C, Herzinger T, Flaig MJ, Brenner M, Borelli C, Degitz K. The efficacy of photodynamic therapy in actinic cheilitis of the lower lip: a prospective study of 15 patients. Dermatol Surg. 2007;33:825-30.

ENDEREÇO PARA CORRESPONDÊNCIA / MAILING ADDRESS:

Luís Torezan

Rua Dr. Eduardo de Souza Aranba, 99, conj. 11, Itaim Bibi, 04543110 São Paulo SP

E-mailtorezanluis@uol.com.br

Como citar este artigo/How to cite this article: Torezan L, Niwa ABM, Festa Neto C. Terapia fotodinâmica em dermatologia: princípios básicos e aplicações. An Bras Dermatol. 2009;84(5):445-59. 